\title{
Evidence for handheld electronic medical records in improving care: a systematic review Robert $\mathrm{CWu}^{* \dagger 1}$ and Sharon E Straus ${ }^{\dagger 1,2}$
}

\author{
Address: ${ }^{1}$ Division of General Internal Medicine, University Health Network, Toronto, Ontario, Canada and ${ }^{2}$ Knowledge Translation Program, \\ University of Toronto, Toronto, Ontario, Canada \\ Email: Robert C Wu* - robert.wu@uhn.on.ca; Sharon E Straus -sharon.straus@utoronto.ca \\ * Corresponding author †Equal contributors
}

Published: 20 June 2006

BMC Medical Informatics and Decision Making 2006, 6:26 doi:10.1 186/1472-6947-6-26

This article is available from: http://www.biomedcentral.com/I472-6947/6/26

(c) 2006 Wu and Straus; licensee BioMed Central Ltd.

This is an Open Access article distributed under the terms of the Creative Commons Attribution License (http://creativecommons.org/licenses/by/2.0), which permits unrestricted use, distribution, and reproduction in any medium, provided the original work is properly cited.
Received: 22 March 2006

Accepted: 20 June 2006

\begin{abstract}
Background: Handheld electronic medical records are expected to improve physician performance and patient care. To confirm this, we performed a systematic review of the evidence assessing the effects of handheld electronic medical records on clinical care.

Methods: To conduct the systematic review, we searched MEDLINE, EMBASE, CINAHL, and the Cochrane library from 1966 through September 2005. We included randomized controlled trials that evaluated effects on practitioner performance or patient outcomes of handheld electronic medical records compared to either paper medical records or desktop electronic medical records. Two reviewers independently reviewed citations, assessed full text articles and abstracted data from the studies.

Results: Two studies met our inclusion criteria. No other randomized controlled studies or nonrandomized controlled trials were found that met our inclusion criteria. Both studies were methodologically strong. The studies examined changes in documentation in orthopedic patients with handheld electronic medical records compared to paper charts, and both found an increase in documentation. Other effects noted with handheld electronic medical records were an increase in time to document and an increase in wrong or redundant diagnoses.

Conclusion: Handheld electronic medical records may improve documentation, but as yet, the number of studies is small and the data is restricted to one group of patients and a small group of practitioners. Further study is required to determine the benefits with handheld electronic medical records especially in assessing clinical outcomes.
\end{abstract}

\section{Background}

Patient safety is an increasingly important issue in care delivery. The Institute of Medicine report estimates that 44,000 to 94,000 deaths are caused annually from medical errors [1]. Studies estimate that $3-17 \%$ of inpatients experience adverse events significant enough to prolong hospitalization, cause significant morbidity, or lead to death [2-10]. Errors can be caused by a number of factors including lack of information about the patient or lack of knowledge about a therapy. In a study of errors in medication prescribing, 30\% were related to knowledge in drug therapy and $29 \%$ were due to a lack of patient information[11]. Decreased uptake of the evidence by the practitioner or patient can also cause errors of omission[12]. 
Handheld computers may improve quality of care by saving clinicians time in the accessing, retrieving and recording of data, allowing clinicians to focus more on patient care [13-15]. They can also provide clinical decision support at the point-of-care such as during electronic prescribing[16]. Improving access to knowledge databases at the point-of-care may also improve translation of knowledge into practice[17]. As well, many groups feel that mobile access to electronic medical records is the only way forward for certain complex care areas such as the emergency department $[18,19]$.

Surveys estimate that approximately half of practicing physicians own a handheld computer[20,21]. Recent focus group sessions of 54 doctors from a variety of practice settings in the United States revealed that many use mobile computers in clinical practice, and some use them to access the electronic medical record[22]. They perceived the benefits to be improved productivity and accessibility of information as well as great potential to improve patient safety and quality of care. However, the true benefit of handheld computers is unclear and to help understand this issue, we conducted a systematic review of the evidence for mobile or handheld electronic medical records (EMRs) in improving patient care.

\section{Methods \\ Definitions}

For this paper, we used the American Health Information Management Association's definition of the electronic medical record: the computerization of health record content and associated processes usually referring to an electronic medical health record in a physician office setting or a computerized system of files[23]. Since we could not find a standard definition for a handheld EMR, we defined it as the computerization of health record content and associated processes available through a handheld computer, personal digital assistant (PDA) or tablet. Thus, for purposes of this study, handheld EMRs were not required to be integrated to or interfaced with a hospital medical record system.

\section{Search strategy}

We searched MEDLINE, CINAHL, EMBASE, and the Cochrane Library from 1966 to September 2005 using the following search strategy: handheld technology AND electronic medical record AND randomized controlled trial. For handheld technology, the following terms were used: computer peripherals; computers, handheld; handheld; mobile; pda; personal digital assistant; palm pilot; palmtop; point of care; tablet; and wireless. The electronic medical record search used the following terms: computer communication network; electronic chart; e-chart; epr; ehr; electronic health record; electronic patient record; hospital information systems; and medical records. To identify randomized controlled tri- als (RCTs), we used the search strategy that has been developed and refined by the Cochrane Effective Practice and Organization of Care Group[24]. We retrieved potentially relevant articles and reviewed their reference lists for additional articles. The full search strategy is available from the authors upon request. There were no language restrictions.

\section{Inclusion criteria}

Articles describing randomized trials or systematic reviews of randomized trials were included. We included studies if 1) we were able to extract relevant data, 2) they included an intervention group that used a handheld electronic medical record for patient care and a control group that was either a desktop EMR or the paper chart, 3) the users of the handheld EMR were clinicians, and 4) the outcomes had to be relevant to clinical care such as a decrease in errors, improved review of information, improved ordering of medications or tests, improved documentation or improved satisfaction.

\section{Outcomes}

Two reviewers independently reviewed the search results and selected relevant publications that met the inclusion criteria. Disagreements were resolved by consensus. In cases of doubt, full text articles were retrieved for review and discussion. Full text articles of abstracts that met the inclusion criteria were retrieved. The investigators independently reviewed all full text articles to confirm that inclusion criteria were met. A standard data abstraction form was used to collect data from each article on the study design including study quality, participants, intervention, setting and relevant outcomes. Study quality was assessed using the following factors: blinding of participants or outcome assessors, concealed allocation, followup, and reliability of primary outcome measures. Differences in assessment by the reviewers were resolved through discussion.

Formal meta-analytic techniques including the pooling of data was not done due to the heterogeneous nature of the clinical interventions as well as the different outcome measures.

\section{Results}

From 1773 citations that were screened, we retrieved 31 full text articles (Figure 1). Two articles met our criteria for inclusion (Table 1). The agreement between the 2 independent reviewers for article inclusion was excellent (kappa = 1.0). Reasons for excluding the articles were the following: 1) the study design was not a RCT $(\mathrm{n}=22) ; 2)$ the intervention was not a mobile $\operatorname{EMR}(\mathrm{n}=5) ; 3)$ the intervention was clinician-focused $(n=1)$, and 4$)$ there were no results reported $(n=1)$. 


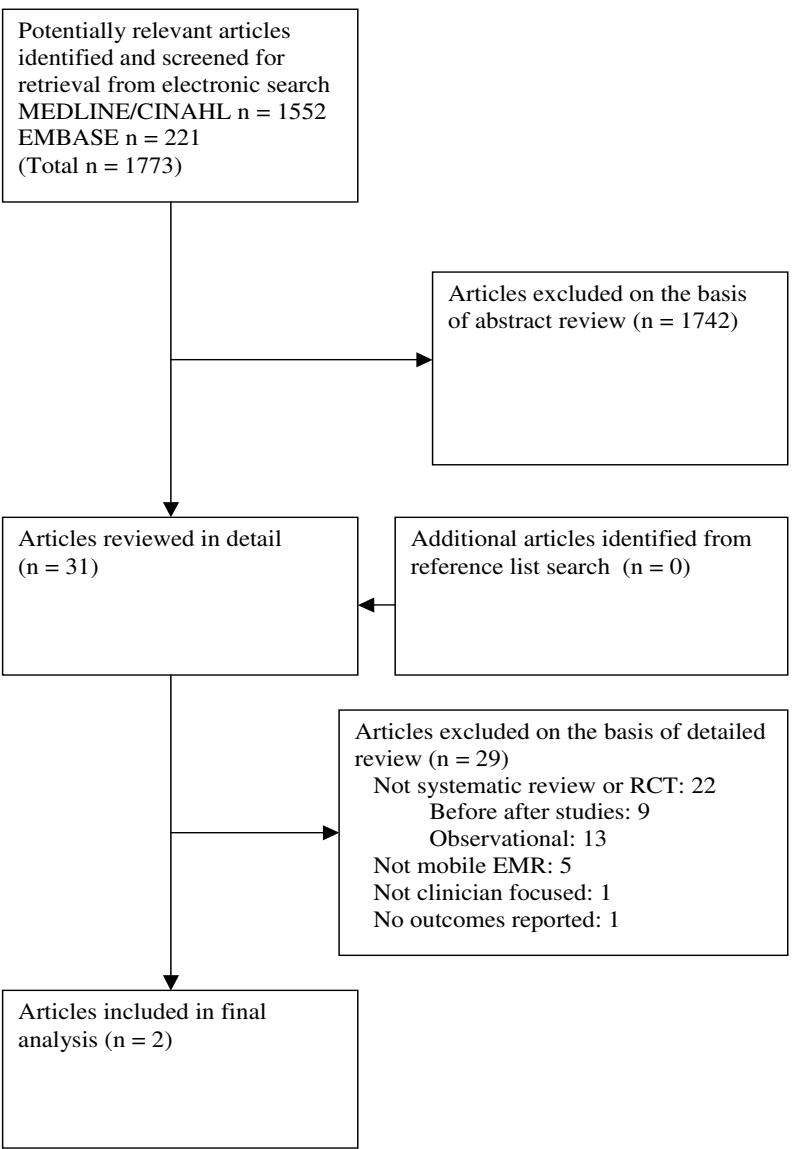

Figure I

Selection process for studies included in the analysis. $* \mathrm{RCT}=$ randomized controlled trial; EMR = electronic medical record.

\section{Description of studies}

The two studies examined 9 practitioners and 152 patients[25,26]. Both studies involved the care of orthopedic patients, and PDAs were compared to paper charts for purposes of documentation in both studies (Table 1).

VanDenKerkhof et al [25] looked at the use of PDAs by anesthesiologists working on a pain service and caring for orthopedic patients. Patients were randomized to have the anesthesiologist document their clinical assessment and place orders either on a PDA or on the paper chart as usual. The primary outcomes were the encounter time (defined as the time from reviewing patient information to assessing the patient and completing charting) and comprehensiveness of documentation. The encounter time was 6.1 minutes in the PDA group and 4.6 minutes in the paper chart group ( $\mathrm{p}$ value $=0.00$ ). Documentation comprehensiveness was determined by looking at five pain and side effect variables for each group. This was significantly better in the PDA group for three of the five var- iables including nausea, pruritus and sedation. For the two other variables, pain score and hypotension, there was a trend to increased documentation with the PDA group, but this was not statistically significant ( $\mathrm{p}$ value 0.07 for both).

Stengel et al[26] studied 6 house officers providing care for orthopedic inpatients. Patients were randomized to have the house officers document diagnoses and clinical history for each patient using either the PDA or the standard paper form. The primary outcome was the number of documented ICD (International Classification of Diseases) diagnoses that were correct as determined by chart review. They found that more diagnoses were entered using the PDA (364 vs $150, \mathrm{P}<0.0001$ ) after adjusting for false or redundant codes. Of note, there were 48 false or redundant codes documented in the PDA group compared with 7 in the control group.

\section{Methodological quality assessment}

Both studies described the method of randomization and the study by Stengel documented concealed allocation. Blinding of outcome assessors was not done in either study due to the nature of the intervention and the choice of primary outcomes. Follow up was excellent in both studies. The reliability of primary outcome measures was difficult to determine. Neither used clinical outcomes but focused instead on comprehensiveness of documentation.

\section{Discussion}

We identified 2 randomized trials that tested two different handheld mobile electronic medical records and both found improved documentation with use of handheld computers. In the study that measured documentation time, the group using PDAs took longer to document. In the study looking at number of diagnoses, the group using PDAs documented more correct diagnoses, but also recorded more redundant or false diagnoses.

There are several previous reviews of handheld applications in health care including reviews by Lu et al[13] and Fischer et al[27]. Both of these reviews provide a comprehensive picture of handheld adoption in healthcare and possible roles of PDAs. Lu characterizes current devices, benefits seen, adoption and complaints. Fischer describes specific uses from descriptive studies. Both articles summarize the literature to describe the functions that PDAs can perform as documented from a variety of study types including before-after and cohort studies. This research complements these papers by systematically reviewing the literature, using rigorous methodology to determine an estimate of the benefit from the highest quality evidence available. 
Table I: Studies of handheld electronic medical records

\begin{tabular}{|c|c|c|c|c|c|c|}
\hline Study, Year & Setting & Patients & Practitioners & $\begin{array}{l}\text { Primary } \\
\text { Function }\end{array}$ & Results & Comments \\
\hline $\begin{array}{l}\text { VanDenKerkof et } \\
\text { al, } 2004 \text { [25] }\end{array}$ & Canada & $\begin{array}{l}\text { Postoperative } \\
\text { orthopedic } \\
\text { patients }(n=72)\end{array}$ & $\begin{array}{l}\text { Anesthesiologists, } \\
\mathrm{n}=4\end{array}$ & $\begin{array}{l}\text { Documentation of } \\
\text { acute pain } \\
\text { management } \\
\text { service }\end{array}$ & $\begin{array}{l}\text { Encounter time } 6.1 \text { minutes } \\
\text { in PDA group vs } 4.6 \\
\text { minutes in paper chart }(p= \\
0.00) \text {. Documentation } \\
\text { significantly better for } 3 \text { of } \\
5 \text { main pain variables. }\end{array}$ & \\
\hline $\begin{array}{l}\text { Stengel et al, } 2004 \\
\text { [26] }\end{array}$ & Germany & $\begin{array}{l}\text { Orthopedic } \\
\text { patients }(n=78)\end{array}$ & $\begin{array}{l}\text { Registrar }(n=1) \text {, } \\
\text { residents }(n=3) \text {, } \\
\text { and medical } \\
\text { students }(n=2) \text { in } \\
\text { orthopedics }\end{array}$ & $\begin{array}{l}\text { Documentation of } \\
\text { daily progress, } \\
\text { diagnoses }\end{array}$ & $\begin{array}{l}\text { More diagnoses entered } \\
\text { using PDA vs paper ( } 4 \text { I I vs } \\
\text { I57). }\end{array}$ & $\begin{array}{l}\text { More incorrect } \\
\text { diagnoses using } \\
\text { PDA vs paper ( } 48 \\
\text { vs } 7 \text { ) }\end{array}$ \\
\hline
\end{tabular}

A recent systematic review found that data collection by handheld computers is an effective alternative to paper methods[28]. There is some similarity between their systematic review and ours. Both review RCTs of handhelds, and both found studies that primarily assessed data collection or documentation. Yet the perspectives are different. Our review focused on the use of handheld electronic medical records, while their review included any form of handheld data collection. None of their included studies involved the use of handheld EMRs by clinicians. Instead, patients or healthy volunteers performed the data collection. Their review did find that data collection by handhelds was faster and preferred by users. The decreased handheld data collection time is different than what we found, but this is likely a result of different users and different applications.

There are several limitations to this study. The results are limited by the quality of studies included. Studies included different 'home-grown' handheld EMR systems so it is hard to generalize to other handheld EMRs. As well, both studies were in orthopedic patients. This clinical setting may be much more uniform and straightforward than other settings with greater variability such as the emergency department. As well, none of the studies looked at impact on clinical outcomes. Finally, studies had to be a RCT to be included in our review. However, it is important to note that there were no controlled trials excluded (Figure 1), minimizing the chance that a high quality study was missed. Less rigorous study designs such as before-after studies were not included.

The strength of this research is that it does synthesize what is currently known and it highlights areas for future research. More rigorous evaluations are required in multiple populations. Preferably, clinical outcomes should be measured. With our search, we found no primary or secondary outcomes evaluating changes in reviewing information, ordering by clinicians or improvement in patient care.
We note that neither study used wireless technology and instead used periodic synchronization. This may be due to wireless being a relatively newer technology. These RCTs were likely conceived years ago prior to widespread adoption of wireless technology. While wireless may have its benefits, it is unclear how well it will work in clinical practice.

\section{Conclusion}

While handheld EMRs may improve patient care by improving documentation, reducing medical errors, and improving decision support, currently there is limited evidence of effectiveness. Further research is required in different populations and also focusing on improvement in patient outcomes. This highlights another area where informatics interventions are being implemented widely without rigorous evaluation.

\section{Competing interests}

The author(s) declare that they have no competing interests.

\section{Authors' contributions}

RCW and SES reviewed the literature search and abstracted information. RCW and SES wrote the manuscript. Both authors read and approved the final manuscript.

\section{References}

I. Kohn LT, Corrigan JM, Donaldson MS: To err is human: building a safer health system. 2000 [http://www.nap.edu/catalog/ 9728.html]. Washington, National Academy Press

2. Brennan TA, Leape LL, Laird NM, Hebert L, Localio AR, Lawthers AG, Newhouse JP, Weiler PC, Hiatt HH: Incidence of adverse events and negligence in hospitalized patients. Results of the Harvard Medical Practice Study I. N Engl J Med 199I, 324:370-376.

3. Thomas EJ, Studdert DM, Burstin HR, Orav EJ, Zeena T, Williams EJ, Howard KM, Weiler PC, Brennan TA: Incidence and types of adverse events and negligent care in Utah and Colorado. Med Care 2000, 38:26I-27I.

4. Vincent C, Neale G, Woloshynowych M: Adverse events in British hospitals: preliminary retrospective record review. $B M$ J 2001, 322:517-519. 
5. Wilson RM, Runciman WB, Gibberd RW, Harrison BT, Newby L, Hamilton JD: The Quality in Australian Health Care Study. Med J Aust 1995, 163:458-47|.

6. Forster AJ, Clark HD, Menard A, Dupuis N, Chernish R, Chandok N Khan A, van Walraven C: Adverse events among medical patients after discharge from hospital. CMAJ 2004, 1 70:345-349.

7. Davis P, Lay-Yee R, Briant R, Schug S, Scott A, Johnson S, Bingley W: Adverse events in New Zealand public hospitals: principa findings from a national survey. Wellington, NZ Ministry of Health; 200I.

8. Davis P, Lay-Yee R, Briant R, Ali W, Scott A, Schug S: Adverse events in New Zealand public hospitals I: occurrence and impact. N Z Med J 2002, I I 5:U27I.

9. Davis P, Lay-Yee R, Briant R, Ali W, Scott A, Schug S: Adverse events in New Zealand public hospitals II: preventability and clinical context. N Z Med J 2003, I I6:U624.

10. Baker GR, Norton PG, Flintoft V, Blais R, Brown A, Cox J, Etchells E, Ghali WA, Hebert P, Majumdar SR, O'Beirne M, Palacios-Derflingher L, Reid RJ, Sheps S, Tamblyn R: The Canadian Adverse Events Study: the incidence of adverse events among hospital patients in Canada. CMAJ 2004, 170:1678-1686.

11. Lesar TS, Briceland L, Stein DS: Factors related to errors in medication prescribing. JAMA 1997, 277:3I2-3I7.

12. Cabana MD, Rand CS, Powe NR, Wu AW, Wilson MH, Abboud PA, Rubin HR: Why don't physicians follow clinical practice guidelines? A framework for improvement. JAMA 1999, 282: $1458-1465$.

13. Lu YC, Xiao Y, Sears A, Jacko JA: A review and a framework of handheld computer adoption in healthcare. Int J Med Inform 2005, 74:409-422.

14. Al Ubaydli M: Handheld computers. BMJ 2004, 328: I |8I-I I 84.

15. Larkin M: Can handheld computers improve the quality of care? Lancet 200I, 358:1438.

16. Ying A: Mobile physician order entry. J Healthc Inf Manag 2003, 17:58-63.

17. Sackett DL, Straus SE: Finding and applying evidence during clinical rounds: the "evidence cart". JAMA 1998, 280:1336-1338.

18. Davidson SJ, Zwemer FLJ, Nathanson LA, Sable KN, Khan AN: Where's the beef? The promise and the reality of clinical documentation. Acad Emerg Med 2004, I I: I I27- I I 34.

19. Handler JA, Feied CF, Coonan K, Vozenilek J, Gillam M, Peacock PRJ, Sinert R, Smith MS: Computerized physician order entry and online decision support. Acad Emerg Med 2004, I I: | I35- | | 4 I.

20. Interactive $\mathrm{H}$ : Physicians' use of handheld personal computing devices increases from $15 \%$ in 1999 to $26 \%$ in 2001 . Health Care Newsletter 200 I: I-4.

21. Horsley A, Forster L: Handheld computers in medicine: the way forward. Postgrad Med J 2005, 8 I: 481 - 482.

22. McAlearney AS, Schweikhart SB, Medow MA: Doctors' experience with handheld computers in clinical practice: qualitative study. BMJ 2004, 328: I I62.

23. AHIMA: Definition of Electronic medical record. Website: http:/ /library ahima org/xpedio/groups/public/documents/ahima/bokI_025042 hcsp 2005 [http://library.ahima.org/xpedio/groups/public/documents/ ahima/bok I 025042.hcsp]

24. Effective Practice and Organisation of Care Group. http:// www epoc. uottawa ca/ 2006 [http://www.epoc.uottawa.ca/]

25. VanDenKerkhof EG, Goldstein DH, Rimmer MJ, Tod DA, Lee HK Evaluation of hand-held computers compared to pen and paper for documentation on an acute pain service. Acute Pain 2004, 6: || $|5-| 2 \mid$.

26. Stengel D, Bauwens K, Walter M, Kopfer T, Ekkernkamp A: Comparison of handheld computer-assisted and conventional paper chart documentation of medical records. A randomized, controlled trial. J Bone Joint Surg Am 2004, 86-A:553-560.

27. Fischer S, Stewart TE, Mehta S, Wax R, Lapinsky SE: Handheld computing in medicine. J Am Med Inform Assoc 2003, 10:139-149.

28. Lane S], Heddle NM, Arnold E, Walker I: A review of randomized controlled trials comparing the effectiveness of hand held computers with paper methods for data collection. BMC Med Inform Decis Mak 2006, 6:23.

\section{Pre-publication history}

The pre-publication history for this paper can be accessed here:

http://www.biomedcentral.com/1472-6947/6/26/prepub
Publish with Bio Med Central and every scientist can read your work free of charge

"BioMed Central will be the most significant development for disseminating the results of biomedical research in our lifetime. "

Sir Paul Nurse, Cancer Research UK

Your research papers will be:

- available free of charge to the entire biomedical community

- peer reviewed and published immediately upon acceptance

- cited in PubMed and archived on PubMed Central

- yours - you keep the copyright
BioMedcentral 